\title{
Investor Attention and Stock Market under the Outbreak of the COVID-19-Based on the Data of Mask Concept Stocks
}

\author{
Bokai Zhang ${ }^{1, \mathrm{a}}$, Xuan Wang ${ }^{2, \mathrm{~b}}$, Meng Rao ${ }^{3, \mathrm{c}}$ \\ ${ }^{1}$ School of Economics, Sichuan Agricultural University, Chengdu, China \\ ${ }^{2}$ School of Finance, Zhongnan University of Economics and Law, Wuhan, China \\ ${ }^{3}$ School of Economics and management, East China Jiaotong University, Nanchang, China
}

\begin{abstract}
With the outbreak of the COVID-19 epidemic, masks have become an important medical material widely concerned by society, which also affects investor sentiment and mask concept stock prices. This article focuses on the impact of investor attention on the rate of return of mask concept stocks. Through the establishment of a panel fixed effect model, it is found that during the epidemic, investor attention to masks has a significant positive impact on the rate of return on mask concept stocks. Then, this article takes the epidemic-related indicators as instrumental variables and uses a two-stage least squares method to carry out the endogenous test, which further verifies the above conclusions and finally puts forward reasonable suggestions.
\end{abstract}

\section{Introduction}

The COVID-19 epidemic, which began in December 2019 , has rapidly fermented and spread worldwide. As of March 29, 2020, there have been more than 600,000 people diagnosed at home and abroad. While the novel coronavirus poses a threat to human life, it also brings shocks to the stock market. In the early stage of the epidemic, antiviral drugs and medical materials were speculated by the market. After investors had the experience of the stock market ups and downs during the "SARS" period, they chose to invest funds in medicine manufacturing companies, and share prices of many pharmaceutical companies soared. At the same time, due to the shortage of medical protective materials, the overall mask sector strengthened against the market. Behind the soaring stocks in these sectors, investor attention has had a huge impact.

The efficient market hypothesis believes that investors in the market are all rational investors and are risk-averse investors. Investors can obtain all the information in the market at no cost and make a rational response based on information obtained. However, with the deepening of research, many market anomalies began to emerge, and behavioral finance challenged traditional finance. Behavioral finance uses investors as the main body of investment market analysis to examine the impact of investors' irrational behavior on the stock market. One of the most important manifestations of investors' irrational behavior is investor sentiment. It is of great significance to study the laws of the stock market based on investor sentiment to explain financial anomalies such as herding, overreaction, and noise trading.

With the rapid development of the Internet and big data, investors have more diversified ways to obtain stock market information, investors have more diverse platforms for expressing opinions, and investor sentiment has further spread with the help of the Internet. Investor data obtained from social media, stock bar reviews, and financial news adds a new perspective to the analysis and prediction of the stock market.

\section{Literature review}

In terms of the measurement of investor sentiment indicators, Huang Hong(2015) chose to use market index or stock price fluctuations to indirectly measure investor sentiment, such as the turnover rate and the rate of new account opening by investors. However, because market index or stock price fluctuations are the result of investor sentiment, the use of such indicators is a measure of the results, not a true reflection of investor sentiment, so this article chooses to use the Baidu search index to obtain investor sentiment direct reflection.

The empirical research on investor sentiment based on network data mining is divided into four types: search index, social network, financial forum, and financial news. The keywords used by investors when using search engines such as Google and Baidu can express investor sentiment. By counting the search volume of vocabulary related to economic activities and containing optimistic or pessimistic sentiments, the investor sentiment can be quantified. DA (2015) built a FEARS index (financial and economics attitudes revealed by search index) based on

azhangbokai@stu.sicau.edu.cn; bwangxuansara@126.com; c20639888139@qq.com 
Google trend data and found that the FEARS index was significantly related to the direction and volatility of short-term stock returns. The data of the social network index was mainly derived from user reviews on social platforms. The content was relatively fragmented and the professionalism was usually low. GIANNINI (2018) explored the impact of investor sentiment on stock mispricing under different information advantages by constructing local investor sentiment and foreign investor sentiment based on Twitter user data. The data of the financial forum index was mainly derived from the content posted by investors in the stock bar (Eastmoney.com, Yahoo Finance, etc.). Sun Kunpeng (2018) used the posting data of China's A-share listed companies to explore the relationship between investor posting sentiment and the risk of future share price crashes. Shi Yong (2017) built stock investor forum investor attention, snowball investor attention, news attention and news sentiment index explored the relationship between social media indicators and the CSI 300 index based on correlation analysis and VAR model, and found that investor concerns and investor sentiment from different sources had different effects on the Chinese stock market.

In the existing research on the impact of investor sentiment on the stock market, Da Debao (2019) used text mining technology and sentiment analysis methods to generate positive and negative three-level and six types of investor sentiment and believed that the construction of the Shanghai stock investor sentiment composite index can improve the accuracy of stock index trend prediction. Zhao Ruwei (2019) used the principal component analysis method to construct the investor sentiment index of the Chinese market. The empirical results showed that it had a different impact on the China Securities 100, China Securities 200, China Securities 500, and China Securities 1000 index constituent stocks. Luo Qi (2020) clarified the difference and interaction between investor sentiment and media sentiment and believed that the irrational behavior of investors and media may reduce the information efficiency of the capital market, which in turn affects stock prices. From the perspective of behavioral economics, Zhang Jihai (2019) explored the internal mechanism of investor sentiment's influence on stock prices and found that investor sentiment affects stock market returns through mechanisms such as systemic deviations, irrational asset bubbles, and herd effects. Song Shunlin (2016) used the IPO company as a research sample and found that market sentiment and specific stock sentiment significantly affected the IPO premium. Tang Yong (2019) found an asymmetric relationship between investor sentiment and the rate of return and volatility of various industries based on industry differences. Lu Jing (2018) expanded the impact of investor sentiment on stocks from a single market to a cross-market, and further divided market sentiment into institutional investor sentiment and individual investor sentiment, and studied these sentiment indicators on AH stock price difference and rate of change impact. Yin Liya (2018) added the investor sentiment index to the Fama-French three-factor model and found that the stock prices of small-cap stocks, high P / E stocks, and high-priced stocks were more sensitive to investor sentiment. Jiang Shangwei (2020) applied the spatial econometric model from the perspective of stock spatial interaction and found that there are significant spatial interactions among financial market stocks, and the spatial interaction is more sensitive to economic distance than geographic location.

\section{Data source and variable description}

\subsection{Data source}

This article integrates multiple stock software (Straight Flush, Eastmoney), and selects 40 mask concept stocks. The data used in this article is daily data from December 4, 2019, to March 26, 2020, including 3,000 observations, of which stock-related data are taken from NetEase Finance, the Baidu index data of masks through the crawler program from Baidu index website (http: //index.baidu.com/v2/index.html\#/) and manual sorting. Baidu index data and stock data correspond by trading day. The epidemic-related data comes from the CSMAR database. The data before January 20, 2019 is obtained by collecting news and Wuhan Municipal Health Commission.

\subsection{Variable description and descriptive statistics}

This article uses the Baidu index of masks to measure the investors' attention to the mask sector. The Baidu index corresponds to the Google index commonly used in foreign literature. The search volume of a certain keyword is used to measure the public's attention to the keyword. The formula for calculating the rate of return of individual stocks is :

$$
\text { rate }_{i, t}=\ln \left(\text { price }_{i, t}\right)-\ln \left(\text { price }_{i, t-1}\right)
$$

TABLE I. VARIABLE DESCRIPTION

\begin{tabular}{|c|c|}
\hline Variable & Description \\
\hline rate & $\begin{array}{c}\text { The rate of return of individual stocks in } \\
\text { the mask sector(\%) }\end{array}$ \\
\hline price & $\begin{array}{c}\text { Closing price of individual stocks in the } \\
\text { mask sector on the day(yuan per share) }\end{array}$ \\
\hline market & $\begin{array}{c}\text { Market rate of return, CSI 300 index rate of } \\
\text { return(\%) }\end{array}$ \\
\hline attention & the Baidu search index of "mask" \\
\hline media & the Baidu media index of "mask" \\
\hline share focus & $\begin{array}{c}\text { the Baidu search index of "mask concept } \\
\text { stock" }\end{array}$ \\
\hline cured & $\begin{array}{c}\text { Cumulative number of patients cured and } \\
\text { discharged due to COVID-19 }\end{array}$ \\
\hline epidemic & Total number of deaths due to COVID-19 \\
\hline
\end{tabular}


TABLE II. DESCRIPTIVE STATISTICS OF VARIABLES

\begin{tabular}{|c|c|l|c|l|c|}
\hline variable & \multicolumn{1}{l|}{$\mathbf{N}$} & \multicolumn{1}{l|}{ mean } & $\begin{array}{l}\text { Standard } \\
\text { deviation }\end{array}$ & min & max \\
\hline rate & 3,000 & $0.33471 \%$ & 0.0423633 & -0.106336 & 0.0966763 \\
\hline market & 3,000 & $-0.0056 \%$ & 0.0170258 & -0.080878 & 0.033859 \\
\hline price & 3,000 & 11.70126 & 8.833799 & 1.93 & 59 \\
\hline attention & 3,000 & 23220.23 & 28542.37 & 631 & 164319 \\
\hline media & 3,000 & 18629.96 & 24611.43 & 406 & 149607 \\
\hline share focus & 3,000 & 527.21 & 636.8413 & 0 & 2833 \\
\hline cured & 3,000 & 20022.48 & 27493.01 & 0 & 74588 \\
\hline epidemic & 3,000 & 1251.187 & 1385.972 & 0 & 3292 \\
\hline
\end{tabular}

\section{4 setting and regression result analysis}

To study the impact of investor attention on the rate of return of mask concept stocks, this article refers to Yang Tao (2019) to establish a fixed-effect model of panel data: rate $_{i, t}=\alpha_{i}+\beta_{1}$ market $_{i, t}+\beta_{2}$ attention $_{t}+$ MonthEffect + WeekEffect $+\varepsilon_{i, t}$

(2)

Model (1) controls the market rate of return (market). To control the calendar effect in the stock market, model (1) also controls the monthly fixed effect and the weekly effect. Since the data used in this article is only two years, therefore, the fixed effect of the year is not considered. Besides, since the COVID-19 epidemic occurred before the annual report and after the third-quarter announcement, the impact of the financial report on the rate of return was not considered. $\beta 2$ measures the impact of changes in investor attention on the rate of return on the mask concept stocks, and the specific results are shown in column 1 of Table 3 . At the same time, this article also studies the influence of investor attention on mask concept stocks (sharefocus) and the number of media reports on masks (media) on the return rate of mask concept stocks. The specific results are shown in the second and third columns of Table 3 respectively.

TABLE III. INVESTOR ATTENTION REGRESSION RESULTS FOR MASK CONCEPT STOCKS

\begin{tabular}{|c|c|c|c|}
\hline market & $\begin{array}{c}0.3807^{* * *} \\
(7.04)\end{array}$ & $\begin{array}{c}0.3974^{* * *} \\
(7.48)\end{array}$ & $\begin{array}{c}0.3841^{* * * *} \\
(7.09)\end{array}$ \\
\hline attention & $\begin{array}{c}7.21 \times 10^{-7^{* * *}} \\
(7.10)\end{array}$ & & \\
\hline sharefocus & & $\begin{array}{c}2.16 \times 10^{-5 * * *} \\
(10.90)\end{array}$ & \\
\hline media & & & $\begin{array}{c}8.41 \times 10^{-7 * * *} \\
(7.14)\end{array}$ \\
\hline Month effect & YES & YES & YES \\
\hline Week effect & YES & YES & YES \\
\hline $\begin{array}{c}\text { Individual } \\
\text { fixed effect }\end{array}$ & YES & YES & YES \\
\hline $\mathrm{N}$ & 3000 & 3000 & 3000 \\
\hline $\mathrm{R}^{2}$ & 0.1131 & 0.1158 & 0.1132 \\
\hline
\end{tabular}

Note: $* * *$, and $* * *$ are significant at $10 \%, 5 \%$, and $1 \%$ confidence levels, and the $t$ value is in parentheses
After controlling the annual fixed effect, monthly fixed effect, intra-week effect, and individual fixed effect, the results in the first column of Table 3 show that investor attention to masks has a significant positive effect on the rate of return of mask concept stocks. Under the condition that other variables remain unchanged, for every 100,000 points of increase in the investor attention to masks, the rate of return of the mask concept stocks will increase significantly by $0.0721 \%$. The results in the second column of Table 3 show that investor attention to mask concept stocks has a significant positive effect on the rate of return of the mask concept stocks. Under the condition that other variables remain unchanged, for every 100,000 points increase in investor's attention to "mask concept stocks", the rate of return of mask concept stocks will increase significantly by $2.16 \%$. The results in column 3 of Table 3 show that for every 100,000 point increase in the number of media reports on masks, the rate of return on mask concept stocks will increase significantly by $0.0821 \%$. Therefore, in general, the attention of investors and media on masks has a significant positive impact on the rate of return of mask concept stocks.

\section{Endogenous inspection}

This article uses the cumulative number of deaths and the cumulative number of cures in the epidemic as instrumental variables to identify the causal relationship between investor attention to masks, mask concept stocks, and media reports on masks and the rate of return on mask concept stocks. Previous studies have shown that investor attention affects stock returns, but at the same time, there are reverse causal situations where changes in stock returns cause investor attention increase, which causes the endogenous problem of investor attention to stock returns. In this paper, the cumulative number of deaths and the cumulative number of cures in the epidemic are introduced as instrumental variables, while, two-stage least squares method is used for analysis. The reasons for using these two variables as instrumental variables are mainly the following: first, these two instrumental variables are exogenous variables for the study of stock price returns; second, during the COVID-19 epidemic, Alipay, National Health Commission of the People's Republic of China, and Dr. Lilac update the relevant data of the COVID-19 epidemic in real-time every day, which 
attract the attention of investors and the media. The specific results are shown in Table 4.

TABLE IV. INVESTOR ATTENTION AND THE MEDIA'S CAUSAL IDENTIFICATION OF MASK CONCEPT STOCKS

\begin{tabular}{|c|c|c|c|}
\hline & (1) & (2) & (3) \\
\hline market & $\begin{array}{l}0.4467^{* * *} \\
(9.30)\end{array}$ & $\begin{array}{l}0.4674^{* * *} \\
(7.35)\end{array}$ & $\begin{array}{l}0.4592^{\text {*** }} \\
(9.41)\end{array}$ \\
\hline attention & $\begin{array}{l}1.96 \times 10^{-} \\
7^{* * *} \\
(3.36)\end{array}$ & & \\
\hline sharefocus & & $\begin{array}{l}7.75 \times 10^{-6^{*}} \\
(1.73)\end{array}$ & \\
\hline media & & & $\begin{array}{l}2.73 \times 10^{-} \\
7 * * * \\
(3.71)\end{array}$ \\
\hline $\begin{array}{l}\text { Month } \\
\text { effect }\end{array}$ & YES & YES & YES \\
\hline $\begin{array}{l}\text { Week } \\
\text { effect }\end{array}$ & YES & YES & YES \\
\hline $\begin{array}{l}\text { Individual } \\
\text { fixed } \\
\text { effect }\end{array}$ & YES & YES & YES \\
\hline $\begin{array}{l}\mathrm{F} \text { (first } \\
\text { stage) }\end{array}$ & 416.023 & 121.344 & 338.706 \\
\hline $\mathrm{N}$ & 3000 & 3000 & 3000 \\
\hline $\mathrm{R}^{2}$ & 0.2401 & 0.1431 & 0.2105 \\
\hline
\end{tabular}

Note: $* * *$, and $* * *$ are significant at $10 \%, 5 \%$, and $1 \%$ confidence levels, and the $\mathrm{z}$ value is in parentheses

The F statistic in the first stage in Table 4 shows that the instrument variable has passed the weak instrument variable test, so it can be used as an effective instrument variable. The results in Table 4 show that the regression coefficients of the variables' attention, sharefocus, and media in the second stage are all positive, indicating that increased investor attention to masks and mask concept stocks are conducive to the rise in the price of mask concept stocks. Compared with Table 3, it can be found that, after considering the possible mutual cause and effect that leads to endogenous problems, investor attention to masks and mask concept stocks still has a significant positive impact on the rate of return of mask concept stocks.

\section{Conclusion}

First of all, through research, this paper finds that investors' increasing interest in masks and mask concept stocks will raise the rate of return of mask concept stocks in the short term. Besides, this article uses the media index as another measure of investor attention and finds that it also shows a significant positive impact on the rate of return of mask concept stocks. The research results corroborate the importance of investment attention to the analysis of stock returns. Besides, media reports on the day also affect stock returns, indicating that media reports and the Internet can disseminate information in time, reducing the cost of investors' access to information, which proves from the side that the effectiveness of the Chinese market has improved.

Furthermore, this article also draws the following conclusions: in sudden public health emergencies, especially COVID-19, due to the sudden increase in demand for masks, the supply cannot keep up. So, the investor's panic about not having a mask has increased significantly and will be directly reflected in the stock price. Therefore, this article suggests that for medical materials such as masks, the government should make a large amount of reserves to prevent the spread of panic during emergencies, and stabilize investor sentiment and the stock market. Also, the government should take measures to deal with the large surplus of masks and the large fluctuations in mask concept stocks after the epidemic.

\section{Acknowledgement}

Supported by Sichuan University Student Innovation Training Program. (Item No.S201910626104) and School-level scientific research interest program(Item No.2019389

\section{References}

1. Huang Hong, Zhang Enhuan, and Sun Hongmei, "Will margin financing increase the impact of investor sentiment on stock index volatility?" China Soft Science, vol. 3, pp.151-161, 2016.

2. Sun Kunpeng, and Xiao Xing, "The influence mechanism of internet social media on investor emotional contagion and stock price collapse risk," Technology and Economics, vol. 37 (06), pp. 93-102, 2018.

3. Shi Yong, Tang Jing, and Guo Kun, "The impact of social media investor attention and investor sentiment on China 's stock market," .Journal of Central University of Finance and Economics, vol. 07, pp. 45, 2017.

4. Dai Debao, and Lan Yusen, "Review on Investor Sentiment and Stock Price Research Based on Internet Text," Wuhan Finance, vol.01, pp. 41-45, January 2019.

5. Zhao Ruwei, Xiong Xiong, and Shen Dehua, "Investor sentiment and stock price crash risk: empirical evidence from the Chinese market," Management Review, vol.31(03), pp. 50-60, 2019.

6. Zhang Jihai, "The impact of investor sentiment on stock prices from the perspective of behavioral economics," Social Science Frontline, vol.12, pp. 235-239, 2019.

7. Song Shunlin, and Wang Yanchao, "How does investor sentiment affect stock pricing? - An empirical study based on IPO companies," Journal of Management Sciences, vol. ,19 (05), pp. 41-55, 2016.

8. Yang Tao, and Guo Mengmeng, "Investor Attention and Stock Market__ Taking PM2.5 Concept Stock 
as an Example," Financial Research, vol. 05, pp. 190206, 2019. 